\title{
JOCKEY CLUB DO PARANÁ: DO SURGIMENTO AOS DIAS ATUAIS
}

Enzo Kitani ${ }^{1}$

Gabriel Bertazolli ${ }^{2}$

\begin{abstract}
Resumo: O texto desenvolve-se por toda a historiografia do Jockey Club do Paraná, do ano de 1873 até os dias atuais. Durante este período, foi levantado os principais nomes do grupo, sua galeria de presidentes e por meio disto fez-se a discussão do turfe como nicho social e sua relação com o estado paranaense.
\end{abstract}

Palavras-chave: Historiografia, Jockey Club do Paraná, Nicho social.

\section{PARANA'S JOCKEY CLUB: FROM FOUNDING TO CURRENT DAYS}

\begin{abstract}
The article is developed over all the historiography of the Parana's Jockey Club, from the year of 1873 until present days. During this period, was searched the most important names from the group, their gallery of presidents, and through them, was done a discussion looking the turf as a socially selective organ and its relation with the politic state of Paraná.
\end{abstract}

Key words: Historiography, Parana’s Jockey Club, Socially selective organ.

\section{Introdução}

Tomamos a data de 02 de dezembro de 1873 como o surgimento do Jockey Club do Paraná, data esta que contou com a formação da primeira Diretoria, formada pelos membros: Coronel Luiz Jácome de Abreu e Souza - presidente honorário; Major Manoel Marcondes de Sá - presidente; Manoel Luiz Agner - Vice-presidente; Nestor Augusto Merocines Borba - $1^{\circ}$ Secretário; Albino Scmmelpfeng $-2^{\circ}$ Secretário; João Batista Ribeiro - Tesoureiro. Não muito após esse dia, foi inaugurado, em 29 de janeiro de 1874, a primeira localização oficial do Jockey Club do Paraná: residia na Rua Marechal Floriano Peixoto o chamado Prado Jácome e tinha uma pista de mil e setecentos metros. (MUNHOZ DA ROCHA, [s.d.])

\footnotetext{
1 Acadêmico de Engenharia de Controle e Automação pela Universidade Tecnológica Federal do Paraná, Campus Curitiba. E-mail: ekitani@alunos.utfpr.edu.br

2 Acadêmico de Engenharia de Controle e Automação pela Universidade Tecnológica Federal do Paraná, Campus Curitiba. E-mail: gabrielberta@outlook.com
} 
Na festa de inauguração, o então chamado "Club de Corridas Paranaense" elabora uma corrida de amadores, com inscrição aberta ao público. Foi apenas em 1887 que o turfe realizou o primeiro Grande Prêmio. Marcado para o sexto dia de janeiro, data também relacionada ao fim do mandato da presidência do clube do Capitão Bento Menezes, corriam nove competidores a distância de 1000 metros pelo prêmio de um conto de réis. Saiu vencedora a égua Itália, de V. Gabardo. (MUNHOZ DA ROCHA, [s.d.])

\section{O Prado Jácome}

Com o período de funcionamento do ano de 1874 a 1898, o Jockey Club do Paraná contou na cadeira da presidência com os seguintes nomes: Manoel Marcondes de Sá, Joaquim Inácio Silveira da Mota Junior, Luiz Manoel Agner, José Pereira dos Santos Andrade, Bento Antonio de Menezes, Benedito Carrão e Ernesto de Campos Lima. ${ }^{3}$

Contou com a mudança de nome duas vezes: em 1882, no mandato de Luiz Manoel Agner, o turfe paranaense passa a ser chamado de "Prado Paranaense", mudança essa que se mantém até 1887, quando novamente se altera o nome e se torna o "Prado Curitibano", contando com arquibancadas maiores na mesma localidade. (RIBAS, [s.d.])

No ano de 1898, ocorre a venda do Prado Curitibano para a construção de um novo hipódromo, plano este elaborado por exigências do público por melhores instalações. É definido então que o Jockey Club do Paraná residiria no bairro de Guabirotuba. (MUNHOZ DA ROCHA, [s.d.])

TABELA 1 - PRESIDENTES DO PRADO JÁCOMEL ${ }^{4}$

\begin{tabular}{|c|c|}
\hline Nome & Breve Biografia \\
\hline Manoel Marcondes de Sá (1873-74) & Vereador de Guarapuava \\
\hline Joaquim Inácio Silveira da Mota Jr. (1875-77) & $\begin{array}{c}\text { Deputado Provincial (1872) e Vice- } \\
\text { presidente do Paraná (1891) }\end{array}$ \\
\hline Luiz Manoel Agner (1882-84, 1888) & $\begin{array}{c}\text { Juiz Municipal de Curitiba (1874) e } \\
\text { Deputado Provincial (1888) }\end{array}$ \\
\hline José Pereira dos Santos Andrade (1885) & Presidente do Paraná (1896-1900) \\
\hline Bento Antonio de Menezes (1886-87) & Maestro da Banda da PM-PR (1861-83) \\
\hline Benedito Carrão (1889) & - \\
\hline Ernesto de Campos Lima (1896-99, 1901) & - \\
\hline
\end{tabular}

Jockey Club do Paraná, GALERIA DOS PRESIDENTES.

\section{Um novo turfe no Paraná}

\footnotetext{
${ }^{3}$ Nomes obtidos na Galeria dos ex-presidentes do clube, disponível em < https://www.jockeypr.com.br/galeria-de-expresidentes/> Acesso em 18 jun. 2019.

${ }^{4}$ Ver Referência das Biografias, no fim do artigo.
} 
No ano seguinte à venda do Prado Jácome, o clube de turfe paranaense passa a se localizar onde atualmente fica a Pontifícia Universidade Católica do Paraná (PUC-PR). Foi inaugurado no dia 25 de junho de 1899, contando com a presença do Governador Santos Andrade e do General Comandante do Distrito. Como evento de inauguração, o turfe contou com uma corrida de bicicletas, de três mil e duzentos metros. (MUNHOZ DA ROCHA, [s.d.]).

No mandato de Joaquim de Andrade, na data 18 de janeiro de 1906, foi inaugurada uma sede do Jockey Club, evento esse que contou com a presença do então presidente do Estado Vicente Machado da Silva Lima, anunciando que "o esforço sobrehumano [sic] dos dignos sportmans [sic] para dar ao Jockey Club a posição notável que hoje ocupa no concerto associativo do Paraná". (MUNHOZ DA ROCHA, [s.d.])

No ano de 1910, o clube de futebol Coritiba F.C. (na época chamado de Coritibano F.C.) aluga o terreno central do hipódromo para treinos e jogos oficiais do clube. (RIBAS, [s.d.])

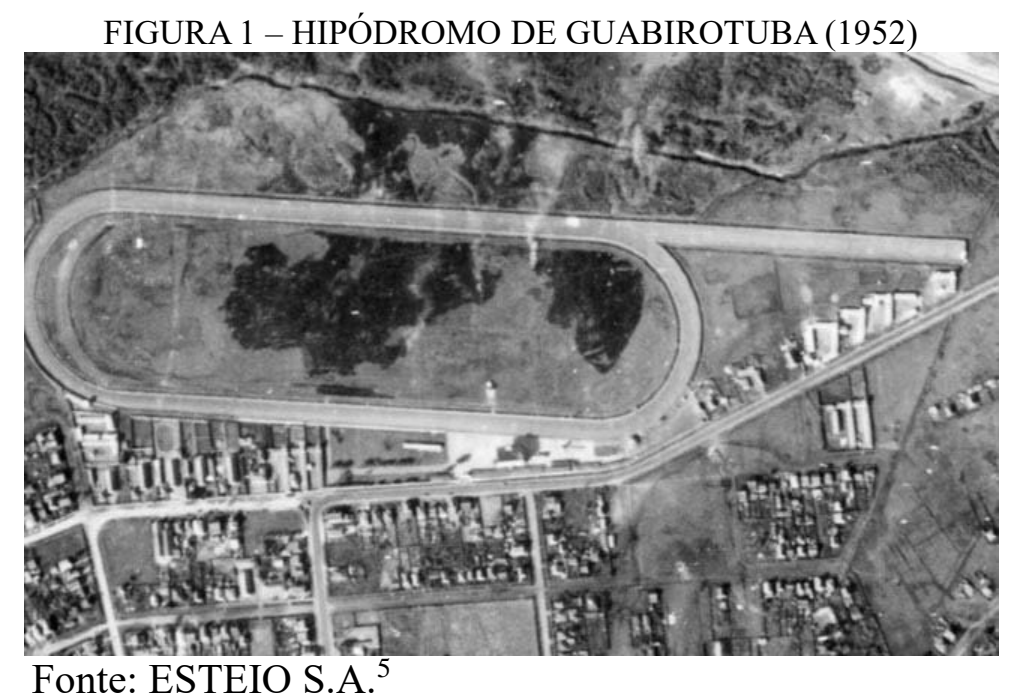

FIGURA 2 - CAMPUS DA PUC-PR NO PRADO VELHO (2012)

\footnotetext{
${ }^{5}$ Disponível em: <https://www.esteio.com.br/variedades/curitiba-ontem-e-hoje/> Acesso em: 03 jul. 2019.
} 
Revista NEP - Núcleo de Estudos Paranaenses, Curitiba, v. 5, n. 2, dez. 2019 Dossiê Oligarquias do Nordeste no Brasil

ISSN: 2447-5548

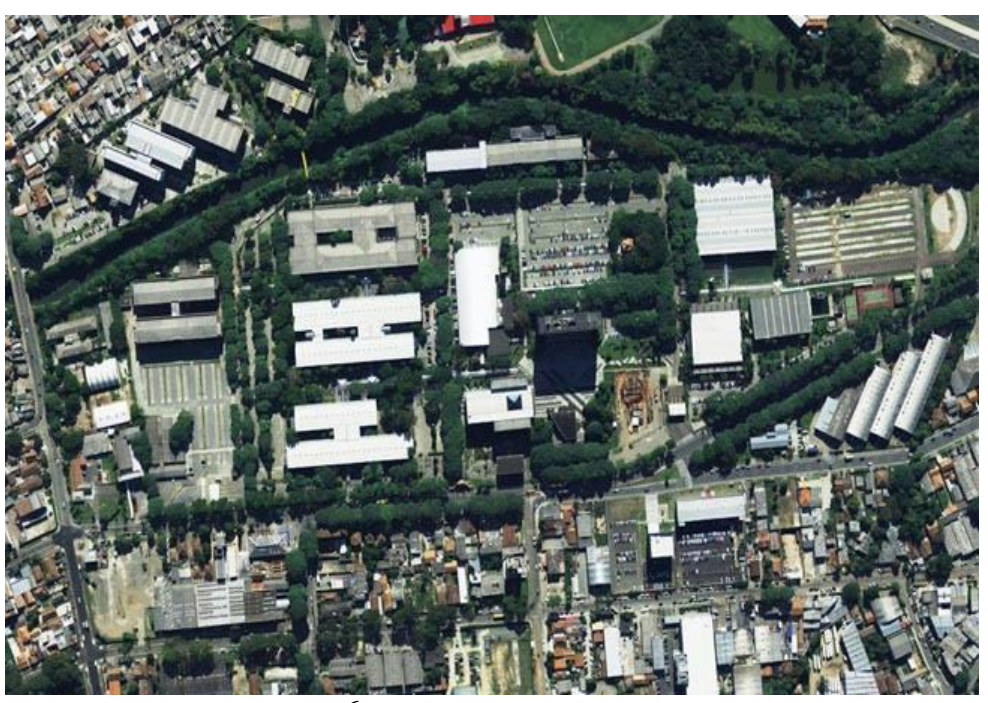

Fonte: ESTEIO S.A. ${ }^{6}$

Os nomes que ocuparam a cadeira da presidência no período de duração do Prado de Guabirotuba (1899 - 1955) foram os seguintes: Ernesto de Campos Lima, Benjamin Pessoa, Eurico de Andrade Neves, Inacio Costa, Joaquim de Andrade, Jorge Meyer, Joaquim Américo Guimarães, Lacob Weiss, Augusto Loureiro, Eduardo Virmond Lima, Albano Drummond dos Reis, Cerqueira Lima, Edgard Guimarães, José de Goes Artigas, José Cândido da Silva Muricy, Napoleão Poeta da Fontoura, Heitor Gurgel do Amaral Valente, Eduardo Virmond Lima, Alexandre Gutierrez, Flavio Macedo, Aramys Athayde, Alô Ticoulat Guimarães, Rubens Amazonas Lima, Linneu Ferreira do Amaral e Pedro Alípio Alves de Camargo. ${ }^{7}$

A ideia de mudança de localidade existia desde 1948, quando alguns ainda defendiam a remodelação do hipódromo de Guabirotuba e outros achavam o terreno inadequado para as corridas. No mandato de Rubens Amazonas Lima, começaram as negociações com o Desembargador Aristoxenes Bittencourt para a obtenção de um terreno no bairro do Tarumã. Em contraposto, no ano de 1949, foi formada uma comissão defendendo a construção de um novo turfe ainda em Guabirotuba, formada por Lineu Ferreira do Amaral (presidente), Raul Gutierrez, Epaminondas Ribeiro, Oscar Rocha e diretoria. (MUNHOZ DA ROCHA, [s.d.]).

O caso ficou parado até o ano de 1950, quando no dia 31 de agosto o Governador do Estado do Paraná Moysés Lupion facilitou a negociação, atribuindo a área de Guabirotuba para o estado e uma área do bairro Tarumã para o Jockey Club do Paraná. Essa obra contou também com o apoio do

\footnotetext{
${ }^{6}$ Ver nota de rodapé 5.

${ }^{7}$ Ver nota de rodapé 3 .
} 
Revista NEP - Núcleo de Estudos Paranaenses, Curitiba, v. 5, n. 2, dez. 2019 Dossiê Oligarquias do Nordeste no Brasil

ISSN: 2447-5548

próximo Governador do Paraná, Bento Munhoz da Rocha Netto. Foi no ano de 1955, no dia 21 de novembro, que realizaram uma festa de despedida, marcando assim o fim do Hipódromo do Guabirotuba. (MUNHOZ DA ROCHA, [s.d.]).

TABELA 2 - PRESIDENTES DO PRADO DO GUABIROTUBA ${ }^{8}$

\begin{tabular}{|c|c|}
\hline Nome & Breve Biografia \\
\hline \multicolumn{2}{|l|}{ Benjamin Pessoa (1900) } \\
\hline \multicolumn{2}{|l|}{ Eurico de Andrade Neves (1902) } \\
\hline \multicolumn{2}{|l|}{ Inácio Costa (1903) } \\
\hline \multicolumn{2}{|l|}{ Joaquim de Andrade (1904-05) } \\
\hline Jorge Meyer (1908) & Prefeito de Curitiba (1896) \\
\hline Joaquim Américo Guimarães (1909-12) & $\begin{array}{l}\text { Neto de Visconde de Nácar e Vereador de } \\
\text { Curitiba }\end{array}$ \\
\hline \multicolumn{2}{|l|}{ Lacob Weiss (1913-14) } \\
\hline \multicolumn{2}{|l|}{ Augusto Loureiro (1915-19) } \\
\hline \multicolumn{2}{|l|}{ Eduardo Virmond Lima (1920-23) } \\
\hline Albano Drummond dos Reis (1924) & $\begin{array}{c}\text { Nascido em } 08 \text { de abril de } 1880 \text {, foi filho do } \\
\text { Inspetor Geral de Higiene Trajano Joaquim } \\
\text { dos Reis. }\end{array}$ \\
\hline \multicolumn{2}{|l|}{ Cerqueira Lima (1925-26) } \\
\hline \multicolumn{2}{|l|}{ Edgard Guimarães (1927-28) } \\
\hline \multicolumn{2}{|l|}{ José de Goes Artigas (1929) } \\
\hline José Cândido da Silva Muricy (1930) & $\begin{array}{c}\text { Tenente Coronel pelo Exército Brasileiro e } \\
\text { Deputado }\end{array}$ \\
\hline \multicolumn{2}{|l|}{ Napoleão Poeta da Fontoura (1933) } \\
\hline \multicolumn{2}{|l|}{ Heitor Gurgel do Amaral Valente (1934) } \\
\hline \multicolumn{2}{|l|}{ Eduardo Virmond Lima (1935) } \\
\hline Alexandre Gutierrez (1936-37) & $\begin{array}{l}\text { Genro de Victor Ferreira do Amaral } \\
\text { (CONSULTAR PROFESSORA) }\end{array}$ \\
\hline \multicolumn{2}{|l|}{ Flavio Macedo $(1938-39,1945)$} \\
\hline Aramys Athayde (1940-44) & $\begin{array}{c}\text { Secretário de Justiça do Paraná, Deputado } \\
\text { Federal (1946-45) e Ministro da Saúde no } \\
\text { mandato João Café Filho (vice de Getúlio } \\
\text { Vargas) }\end{array}$ \\
\hline Alô Ticoulat Guimarães (1946-47, 1956-60) & Deputado Federal (1946-48) \\
\hline Rubens Amazonas Lima (1948-49, 1970-72) & \\
\hline Linneu Ferreira do Amaral (1950-51) & \\
\hline Pedro Alípio Alves de Camargo $(1952-55,1961)$ & \\
\hline
\end{tabular}

Fonte: Jockey Club do Paraná, GALERIA DOS PRESIDENTES.

\section{O re-recomeço}

\footnotetext{
${ }^{8}$ Ver nota de rodapé 4.
} 
A mudança para um novo hipódromo era iminente, e então foi contratado o engenheiro Edmir Silveira D’Avila, marcando o início das obras em 1952 (RIBAS, [s.d]). A obra, que tinha previsão de término para novembro de 1953, foi finalizada apenas em $1955^{9}$. No dia após a festa de despedida, começaram as organizações para a grande mudança.

Em 10 de dezembro de 1955, houve o evento de inauguração, o qual contou com a presença do Governador Bento Munhoz da Rocha Netto e o Prefeito Ney Braga, acompanhados do presidente do clube Pedro Alípio Alves de Camargo. A estréia do novo turfe contou com uma corrida inaugural, apelidada de "Grande Prêmio Inaugural".

Em sua atual localidade, o Jockey Club contou com os seguintes presidentes: Alô Ticoulat Guimarães, Pedro Alipio Alves de Camargo, Alfredo Silvio Colle, Rubens Amazonas Lima, Aramys Bertholdi, Ubaldo de Siqueira, Edison José Mauad, Cezar Evangelista de Oliveira Franco, Eraldo Palmerini, Luis Guilherme Gomes Mussi, Newton Sergio Ribeiro Grein, Roberto Hasemann, Cresus Coutinho Camargo, Cresus Aurélio Wagner Camargo, Paulo Irineu Pelanda e o atual presidente Roberto Belina. ${ }^{10}$

TABELA 3 - PRESIDENTES DO PRADO DO TARUMÃ ${ }^{11}$

\begin{tabular}{|c|c|}
\hline Nome & Breve Biografia \\
\hline Alfredo Silvio Colle (1962-66) & \\
\hline Aramys Bertholdi (1973-84, 1994-98) & \\
\hline Ubaldo de Siqueira (1985-90, 1998-2000) & $\begin{array}{c}\text { Presidente do Coritiba Football Club (1980- } \\
\text { Edison José Mauad (1990-92) }\end{array}$ \\
\hline Cezar Evangelista de Oliveira Franco (1992-94) & Presidente da MAPFRE e do Sindicato \\
\hline Eraldo Palmerini (2001-03) & Advogado do Estado do Paraná \\
\hline Luis Guilherme Gomes Mussi (2003-05) & Diretor do Instituto de Assistência ao Menor \\
\hline Newton Sergio Ribeiro Grein (2005-07) & Filho de Cresus Coutinho Camargo \\
\hline Roberto Hasemann (2007-11) & \\
\hline Cresus Coutinho Camargo (2011-13) & \\
\hline Presus Aurélio Wagner Camargo (2013-15) & \\
\hline Paulo Irineu Pelanda (2015-18) & \\
\hline Roberto Belina (2018-) & \\
\hline
\end{tabular}

Fonte: Jockey Club do Paraná, GALERIA DOS PRESIDENTES.

\begin{tabular}{l}
\hline Informação retirada do patrimônio cultural do paraná. Disponível em: \\
<http://www.patrimoniocultural.pr.gov.br/modules/conteudo/conteudo.php?conteudo=347> . Acesso em: 2 jul. 2019. \\
${ }^{10}$ Ver nota de rodapé 3. \\
${ }^{11}$ Ver nota de rodapé 4.
\end{tabular}




\section{Um nicho social}

O Paraná, desde sua emancipação (1853) e relacionado a economia da erva-mate e do tropeirismo, desenvolveu um papel importante na política nacional (OLIVEIRA, 2001). Sua influência atrelada também ao crescimento de clãs no estado leva a um processo de enraizamento de poder por meio de vínculos familiares e políticos. Como exemplo pode-se citar a família Malucelli, cuja chegada se deu em 1877: o clã teve um crescente em relação a sua influência e o seu poder econômico nos anos seguintes, processo este que esteve sempre relacionando-se a outras famílias, políticos e cooperação interna (COELHO, 2016). O poder não pode ser visto como um processo independente, visto que este está ligado a vários fatores. No texto publicado na NEP “O clã Malucelli - Trajetória, empreendimentos e principais atores no paraná”, 2016, o autor expõe a relação dos projetos da família com a política local e interesses nacionais, assim desconstruindo a ideia, citada no texto de Coelho, do 'self-made man'. Pensando desta forma, percebe-se a importância do contato com pessoas que estão no poder. Ao tentar desenvolver um negócio ou ingressar na política deve-se avaliar vários aspectos do projeto, mas seu sucesso dependerá, também, do apoio que será dado a ele, por parte de influenciadores da área. Pensar o Jockey Club do Paraná, tendo em vista seus associados, é vislumbrar um nicho social claro. O hipismo é um esporte e também um negócio, portanto seleciona uma faixa econômica e social, neste caso de mais alto escalão.

Ao levantar-se dados do turfe do Paraná, percebe-se o poder econômico que este tem. Por exemplo, as suas mudanças de localização e propriedades associadas ao nome. Neste último tópico vale lembrar o lançamento do Jockey Plaza Shopping, no dia 5 de junho de 2019; atualmente, é o maior na capital paranaense, cujo projeto teve um investimento estimado de 650 milhões (SARZI, 2019). Já em relação a influência do órgão, avalia-se a galeria de presidentes, já citada no texto, que está cheia de nomes históricos. Vendo a historiografia destes ali presentes tem-se uma clara visão da ligação do turfe com a política. Advogado do estado, vereador, presidente do estado e deputado são alguns títulos associados a presidência do Jockey Club.

O grupo Jockey, que agora conta com um turfe e um shopping, pode ser visto como um fator formador do Paraná, isto devido ao ambiente ali criado. Nesse caso, um local de socialização e conversa seguro, somente para associados, atribuindo ao grupo, também, um espaço para discussão político-econômica, além de proporcionar o encontro e associação de grandes figuras do Paraná. 
Sendo assim, tem-se o Jockey Club do Paraná como uma extensão do processo de manutenção do poder hierárquico do estado, agregando aos clãs a principal forma de sustentação dos domínios político-econômico ao longo da história (OLIVEIRA, 2001).

Entretanto, pelo Jockey Club do Paraná ser um lugar que conta com grandes números de pessoas conhecidas e pessoas com poder, torna-se então um lugar no qual está mais propício a acontecer as chamadas "polêmicas". Exemplificamos um caso no tópico a seguir.

\section{O caso inacabado de 2009}

O ano de 2009 teve os holofotes voltados ao Jockey Club do Paraná, porém de forma negativa, e não para seus grandes eventos como um turfe. Neste ano um de seus associados, o advogado Rodrigo Muniz Santos, denunciou a incoerência envolvendo uma assembleia do clube no ano de 2007.

$\mathrm{O}$ evento questionado foi uma assembleia que visava a venda de dois terrenos, pelo valor de 20,1 milhões de reais (LOPEZ, 2009). Para efetivar a venda seriam necessários, de acordo com o regulamento interno do turfe, a presença de 200 associados. Uma primeira tentativa foi feita no dia 29 de maio de 2007; nesta data, a assembleia não atendeu o requisito de sócios mínimos necessários (quórum). Em seguida, no dia 5 de julho do mesmo ano, houve um evento para o mesmo enfoque que conseguiu 218 assinaturas, logo permitindo a venda dos terrenos (RIBAS, 2015). Porém dois anos depois, em 8 de abril de 2009, um membro associado alega que não compareceu aquela assembleia e que sua assinatura havia sido falsificada.

O presidente na época (2009), Roberto Hasemann, alegou que que haviam sim mais de 200 pessoas na assembleia e que uma pequena minoria foi contra, assim defendendo a validade da venda, pontuando que sua diretoria era a responsável pelo clube em 2007 e obtendo sua reeleição em 2009, um mês antes da acusação (LOPEZ, 2009).

Devido a investigação da ata da reunião foi possível averiguar algumas inconsistências, como: assinaturas de sócios que alegam não ter comparecido, o acusador e o jornalista Candido Gomes Chaves por exemplo, nomes de sócios já falecidos, como o advogado e ex-deputado Júlio Rocha Xavier, falecido em 1994, além de constar nomes duplicados e de não associados (LOPES, 2009). Com tantas provas o caso foi passado para a NURCE (Núcleo de Repressão a Crimes Econômicos) já que se mostrou um caso de fraude para ganho econômico por parte da instituição. Toda via o caso 
que foi levado a júri em 2012 termina como caso arquivado, sem alteração nas consequências levadas pela fraude (RIBAS, 2015).

\section{Considerações Finais}

Ao analisar o contexto histórico-político do Jockey Club do Paraná, podemos chegar à conclusão de que o clube em si é um lugar de status. Contou, em sua história, com a presença de sobrenomes como Santos Andrade, Guimarães, Muricy, Gutierrez, Ferreira do Amaral e entre outros, demonstrando a força que o alto-escalão do Jockey contém. Também, em suas obras, contou sempre com apoio político dos prefeitos e governadores de Estado, assim como grandes divulgações em jornais de época. Analisa-se também as localizações dos lugares, tanto atuais quanto antigos: a primeira localização, o Prado Jácome, localizava-se no centro de Curitiba. O segundo, o Prado do Guabirotuba, influenciou o nome do bairro atual, o "Prado Velho". O terceiro, e atual, o Prado do Tarumã, com a construção do novíssimo Jockey Plaza Center, contou com obras em seus arredores, em grandes avenidas como a Av. Victor Ferreira do Amaral e também na rua R. Konrad Adenaue.

Com isso, fica claro que o Jockey Club do Paraná é um lugar ideal para conversas de alto escalão e eventos de tal porte. Além de que, por se tratar de um clube de corrida de cavalos, é também um lugar considerado tradicional, na cultura brasileira.

\section{Referências}

MUNHOZ DA ROCHA, Raphael. A história do jockey club do paraná. [s.d.].

RIBAS, Luiz Renato. Na pista há 144 anos. [s.d.].

RIBAS, Luiz Renato. Enquanto isso, no Jockey Club do Paraná. Disponível em: $<$ http://www.zebeto.com.br/2015/04/13/enquanto-isso-no-jockey-club-doparana/\#.XPK29ohKhhF >. Acesso em: 5 jun. 2019.

LOPES, José Marcos. Sócios acusam o Jockey de fraude. Disponível em: $<$ https://www.gazetadopovo.com.br/vida-e-cidadania/socios-acusam-o-jockey-de-fraudebk1dw0zfqwsgf9phvu5q1no7i// >. Acesso em: 5 jun. 2019.

Jockey Club do Paraná, GALERIA DOS PRESIDENTES. Disponível em: $<$ https://www.jockeypr.com.br/galeria-de-ex-presidentes/>. Acesso em: 5 jun. 2019.

SARZI, Lucas. Maior shopping de Curitiba inaugura nesta quarta-feira. Conheça detalhes!. 
Disponível em <https://www.tribunapr.com.br/noticias/curitiba-regiao/maior-shopping-de-curitibainaugura-nesta-quarta-feira-conheca-detalhes/>. Acesso em 30 jun. 2019.

COELHO, Nicolas Paes. O clã Malucelli - trajetória, empreendimento e principais atores no Paraná. Revista NEP, Curitiba, v.3, n. 1, p. 17-35, 2017.

OLIVEIRA, Ricardo Costa de. O Silêncio dos Vencedores: genealogia, classe dominante e Estado no Paraná. Curitiba: Moinho do Verbo, 2001.

\section{Referência das Biografias}

Academia de Letras, Artes e Ciências de Guarapuava. Disponível em: $<$ https://www.alacguarapuava.com/manoel-marcondes-de-sa $>$. Acesso em: 29 jun. 2019.

Casa Civil do Paraná. Disponível em: http://www.casacivil.pr.gov.br/modules/conteudo/conteudo.php?conteudo=32>. Acesso em: 29 jun. 2019.

Relatorio com que o Exm. Sr. Dr. Manuel Pinto de Souza Dantas Filho Passou ao Exm. Snr. Dr. João José Pedrosa A Administração da Provincia Em 4 de Agosto de 1880. Disponível em: $<$ http://www.arquivopublico.pr.gov.br/arquivos/File/RelatoriosGoverno/Ano1880MFN675.pdf $>$. Acesso em 29 jun. 2019.

CAVAssin AlVES, Alessandro. A Província do Paraná (1853-1889). A Classe Política. A Parentela no Governo. [2014]

Casa Civil do Paraná. Disponível em: $<$ http://www.casacivil.pr.gov.br/modules/conteudo/conteudo.php?conteudo=41 > Acesso em: 29 jun. 2019.

Polícia Militar do Paraná. Histórico Banda PMPR. Disponível em: $<$ http://www.pmpr.pr.gov.br/modules/conteudo/conteudo.php?conteudo=586 $>$. Acesso em: 29 jun. 2019.

Prefeitura Municipal de Curitiba. Relação dos Prefeitos de Curitiba. Disponível em: $<$ https://www.curitiba.pr.gov.br/conteudo/relacao-dos-prefeitos-de-curitiba/4 $>$. Acesso em $29 \mathrm{jun}$. 2019.

Furacao.com. Saiba quem foi Joaquim Américo Guimarães. Disponível em: $<$ http://furacao.com/2014/09/06/saiba-quem-foi-joaquim-americo-guimaraes/>. Acesso em: 29 jun. 2019.

Geni. Disponível em $\quad<\underline{\text { https://www.geni.com/people/Albano-Drummond-dos- }}$

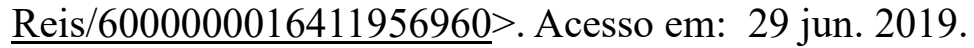

TIBILETTI DE LARA, Jorge. Higienismo, saúde e doença: Trajano Joaquim dos Reis e Inspetoria de Higiene do Paraná (1889-1919). [s.d]. 
Museu Maçônico Paranaense. Disponível em:

$<$ http://www.museumaconicoparanaense.com/MMPRaiz/Autoridades PR/GOEPR928 930-

$\underline{\text { Jose Candido da Silva Muricy.htm> }}$. Acesso em 29 jun. 2019.

Secretaria da Justiça, Trabalho e Direitos Humanos. Galeria de Secretários de Justiça. Disponível em:

$<$ http://www.justica.pr.gov.br/modules/galeria/detalhe.php?foto $=271 \&$ evento $=30>$. Acesso em: 29 jun. 2019.

FGV. CPDOC. Disponível em: $<$ http://www.fgv.br/cpdoc/acervo/dicionarios/verbetebiografico/aramis-taborda-de-ataide $>$. Acesso em: 29 jun. 2019.

FGV. CPDOC. Disponível em: $<$ http://www.fgv.br/cpdoc/acervo/dicionarios/verbetebiografico/guimaraes-alo-ticoulat>. Acesso em: 29 jun. 2019.

Galopando.com.br. Harás Xará. Disponível em: $<$ http://galopando.com.br/haras-xara/>. Acesso em: 29 jun. 2019.

Memórias Paraná. Eraldo Palmerini (2015) Turfe - Valli del Pasubio - Itália. Disponível em: $<$ http://memoriasparana.com.br/eraldo-p-palmerini-2015-turfe-valli-del-pasubio-italia/> . Acesso em: 29 jun. 2019.

Câmara Municipal Curitiba. Homenagem a Newton Grein é aprovada por vereadores de Curitiba. Disponível em: $<$ https://www.cmc.pr.gov.br/ass det.php?not=26884\#\&panel1-1 $>$. Acesso em 29 jun. 2019. 